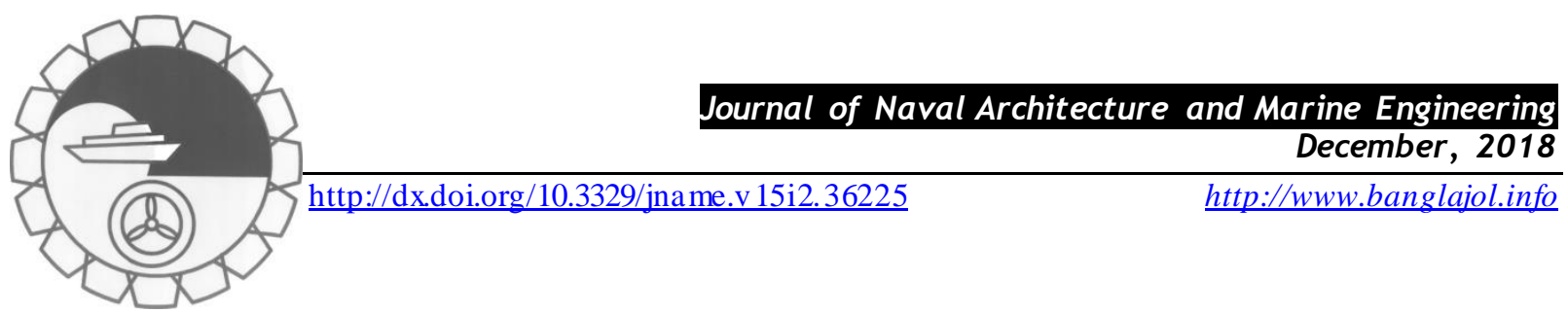

\title{
CFD INVESTIGATION ON STEADY AND UNSTEADY PERFORMANCES OF CONTRA-ROTATING PROPELLERS
}

\author{
P. Kaewkhiaw
}

Department of Maritime Engineering, Faculty of International Maritime Studies, Kasetsart University, Sri Racha Campus, 199 Moo 6, Sukhumvit Road, Tung Sukla, Sri Racha, Chonburi 20230, Thailand, prachakon.ka@ku.th

\begin{abstract}
:
The realistic flow on each blade of the front and rear propellers with contra-rotating propellers (CRPs) is very much complex due to interaction forces which affect to the actual efficiency of the propeller blades. The wake of CRPs at the gap between the front and rear propellers have influence to the variation of propeller performance for the front and rear propellers. So this paper presents the numerical simulation of propeller performance on CRPs with steady method in the first. Second, it is applied to evaluate the propeller performance with unsteady method in time accuracy and investigate the wake on a transverse plane between the front and rear propellers and a transverse plane located downstream of the rear propeller. The wake is analyzed through velocity vector magnitude contours. The numerical investigations are conducted using the Computational Fluid Dynamics (CFD) based on the Reynolds Averaged Navier-Stokes equations (RANS). The calculation results have been compared with the experimental results and found satisfactory .
\end{abstract}

Keywords: RANS, CFD, contra-rotating propellers, propeller performance.

\section{NOMENCLATURE}

\begin{tabular}{llll}
$C R P s$ & Contra-rotating propellers & $V_{A}$ & Uniform inflow velocity \\
$R A N S$ & Reynolds-Averaged Navier-Stokes & $\eta_{o}$ & Propeller efficiency \\
$E V M s$ & Eddy-Viscosity models & $n$ & Propeller rotational speed \\
$R S M s$ & Reynolds-Stres models & \multicolumn{1}{c}{ Greek symbols } \\
SST $k$ - $\omega$ & Shear Stress Transport $k-\omega$ & $\delta_{i j}$ & Kronecker delta \\
$T_{F}$ & Front propeller thrust & $-\rho \overline{u_{i}^{\prime} u_{j}^{\prime}}$ & Unknown Reynolds Stresses \\
$T_{A}$ & Rear propeller thrust & $\mu_{t}$ & Eddy Viscosity \\
$Q_{F}$ & Front propeller torque & $k$ & Kinetic energy \\
$Q_{A}$ & Rear propeller torque & $\delta_{i j}$ & Kronecker delta \\
$K_{T F}$ & Thrust coefficient of front propeller & $G_{\omega}$ & Generation of $\omega$ \\
$K_{T A}$ & Thrust coefficient of rear propeller & $\Gamma_{k}$ & Effective diffusivity of $k$ \\
$K_{Q F}$ & Torque coefficient of front propeller & $\Gamma_{w}$ & Effective diffusivity of $\omega$ \\
$K_{Q A}$ & Torque coefficient of rear propeller & $Y_{k}$ & Dissipation of $k$ due to turbulence \\
$K_{T}$ & Total thrust coefficients & $Y_{\omega}$ & Dissipation of $\omega$ due to turbulence \\
$K_{Q}$ & Total torque coefficients & $D_{\omega}$ & Cross-diffusion term \\
$D_{F}$ & Front propeller diameter & $S_{k}, S_{\omega}$ & User-defined source terms \\
$J$ & Advance coefficient & $\overline{G_{k}}$ & Generation of turbulence kinetic energy \\
& & & due to mean velocity gradients
\end{tabular}

\section{Introduction}

The contra-rotating propellers (CRPs) are classified to energy saving devices and extensively us ed in modern ships because it is high-efficiency propulsion systems comparing a single propeller. The total powers of CRPs are separated into to the front and rear propellers so on each propeller loading are reduced, therefore the 1813-8235 (Print), 2070-8998 (Online) @ 2018 ANAME Publication. All rights reserved. Received on: April 2018 
inception of cavitation is delayed. In addition, each propeller of CRPs rotates in opposite directions thus total rotation in downstream are canceled which reason that the total torque of them is balanced so on it saves energy.

The CRPs were interested in many researchers on the subject of the experiments and computational methods. The brief summary of that mention such as Miller $(1976,1981)$ measured the forces on contra-rotating propellers for uniform inflow and application for torpedoes with two CRPs model scale propellers. Hoshino (1994) conducted the experimental of unsteady propeller shaft forces on a CRPs operating behind a ship. Paik et al. (2005) analyzed of vortex flow behind a rotating propeller using PIV in a cavitation tunnel.

Simultaneously, the lifting surface theory and vortex lattice method have long been applied to analyze the CRPs performances such as Tsakonas et al. (1983) proposed the prediction of steady, unsteady loads and hydrodynamic forces on CRPs by using linearized unsteady-lifting surface theory. Yang et al. (1991, 1992) calculated of steady and unsteady performances of CRPs by lifting surface theory. Hoshino (1994) predicted the unsteady propeller shaft forces by a lifting surface theory based on quasi-continuous method. Paik et al. (2000) proposed the analysis of CRPs in steady flow by a vortex lattice method. Gu and Kinnas (2003) analyzed the modeling of CRPs and ducted propeller via coupling of a vortex-lattice with a finite volume method. Grassi et al. (2010) presented the design and analysis of CRPs comparison the numerical by lifting surface method and experimental results. Concurrently, Inukai (2011) developed the CRPs with tip-raked fins based on a quasicontinuous vortex method. Inukai et al. (2014) evaluated the steady performance of CRPs including wake alignment using a simplified surface panel method "SQCM". Inukai et al. (2015) offered the prediction of steady CRPs performance with rudder based on a simplified surface panel method "SQCM".

After that, the computer performances are improved therefore the RANS CFD is carried out to analyze the propeller performances such as Kaewkhiaw et al. (2011) studied the application of nonlinear turbulence models for marine propulsors. Kaewkhiaw and Ando (2014) simulated unsteady propeller performances with inclined shaft propeller arrangement by using CFD.

The present paper proposed the RANS numerical simulation to evaluate the thrust, torque coefficients and propeller efficiency of the front and rear propellers for two CRPs models with the steady meth od (time average) in the first order. Second, it has been applied to unsteady method in time accuracy which studied propeller performance of front and rear propellers in the time step size. Moreover, the wake effects have been generated by the front and rear propellers which are influent the creating forces on each blade including propeller efficiency have been investigated. The wake is analyzed through velocity vector magnitude contours on a plane between the front and rear propellers and on a plane which located downstream of rear propeller. The calculated results are compared the measurement data of David Taylor Naval Ship Research and Development Center, that reported by Miller (1976, 1981).

Table 1: Principal particular of CRPs

\begin{tabular}{|c|c|c|c|}
\hline Model name & 3686 & $3687 \mathrm{~A}$ & 3849 \\
\hline Position & Front & Rear & Rear \\
\hline Numbers of blade & 4 & 4 & 5 \\
\hline Diameter[mm] & 305.2 & 299.1 & 299.3 \\
\hline Expanded area ratio & 0.303 & 0.324 & 0.379 \\
\hline Pitch at 0.7R [mm] & 394 & 396.8 & 385.3 \\
\hline Direction of rotation & Counterclockwise & Clockwise & Clockwise \\
\hline Section meanline & \multicolumn{3}{|c|}{ NACA a $=0.8$} \\
\hline Section thickness distribution & \multicolumn{3}{|c|}{$J=1.1$} \\
\hline Design advance coefficient & \multicolumn{3}{|c|}{} \\
\hline
\end{tabular}

\section{Contra-Rotating Propeller Models}

The principal particulars of the 3686-3687A and 3686-3849 CRPs are presented in Table 1. The 3686-3687A CRPs are consisted the 3686 propeller (front propeller) which is four blades and 3687A propeller (rear propeller) which has four blades. In addition, another one is 3686-3849 CRPs are comprised the 3686 propeller 
(front propeller) and 3849 propeller (rear propeller) respectively. The 3849 propeller is set five blades. The details of the both CRPs geometrical particulars can be found in Miller $(1976,1981)$. Figure 1 shows the models of the both CRPs. The axial spacing between centerlines of the front and rear propellers are defined $43.2 \mathrm{~mm}$ for the both CRPs. The experiment conducted in uniform inflow. The rotational speed as same between the front and rear propellers is equal to $12 \mathrm{rps}$ with the both CRPs.
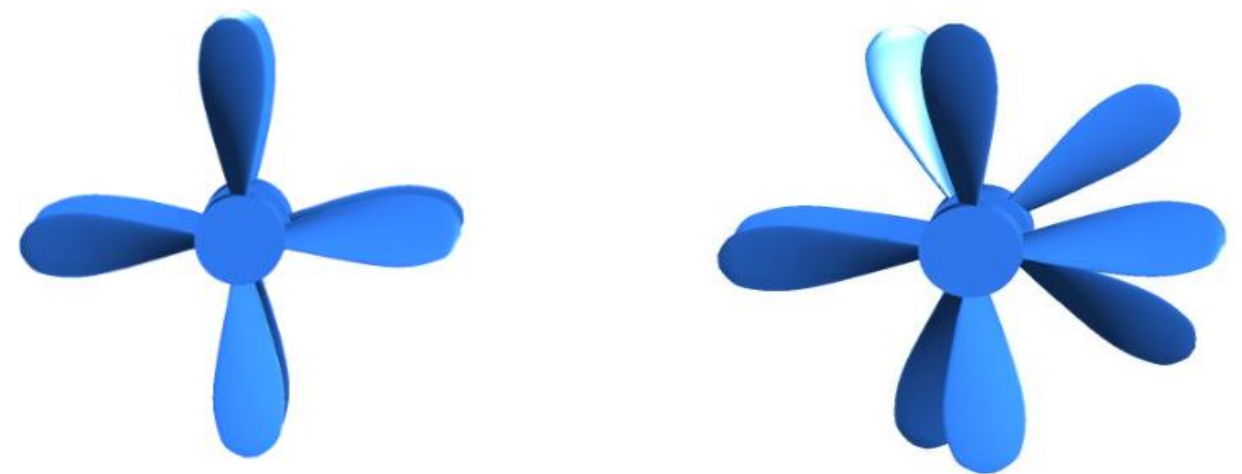

Fig. 1: 3686-3687A (Left) and 3686-3849 (Right) propellers

\section{Numerical Methods}

The flow is simulated by enforcing the conservation of mass and momentum. The conservation equations are commonly known as Navier-Stokes Equations. It was used in their incompressible form. The general of RANS equations for continuity can be written in Cartesian tensor form as follows:

$\frac{\partial \rho}{\partial t}+\frac{\partial\left(\rho u_{i}\right)}{\partial x_{i}}=0$

The momentum equations as follows:

$\frac{\partial\left(\rho u_{i}\right)}{\partial t}+\frac{\partial\left(\rho u_{i} u_{j}\right)}{\partial x_{j}}=-\frac{\partial p}{\partial x_{i}}+\frac{\partial}{\partial x_{j}}\left[\mu\left(\frac{\partial u_{i}}{\partial x_{j}}+\frac{\partial u_{j}}{\partial x_{i}}-\frac{2}{3} \delta_{i j} \frac{\partial u_{i}}{\partial x_{i}}\right)\right]+\frac{\partial}{\partial x_{j}}\left(-\rho \overline{u_{i}^{\prime} u_{j}^{\prime}}\right)$

RANS modeling can be classified into two groups: Eddy-Viscosity Models (EVMs) and Reynolds-Stress models (RSMs). EVMs are based on the Boussinesq hypothesis where the Reynolds stresses are proportional to the rates of strain as follows:

$-\rho \overline{u_{i}^{\prime} u_{j}^{\prime}}=\mu_{t}\left(\frac{\partial u_{i}}{\partial x_{j}}+\frac{\partial u_{j}}{\partial x_{i}}\right)-\frac{2}{3} \rho k \delta_{i j}$

Where $\left(\delta_{i j}=1\right.$ if $i=j$ and $\delta_{i j}=0$ if $\left.i \neq j\right)$. The Shear Stress Transport, SST $k$ - $\omega$ turbulence model is employed to calculate Reynolds-Stress term in the RANS equations. The SST $k-\omega$ equations are written as follows:

$$
\begin{aligned}
& \frac{\partial}{\partial t}(\rho k)+\frac{\partial}{\partial x_{i}}\left(\rho k u_{i}\right)=\frac{\partial}{\partial x_{j}}\left(\Gamma_{k} \frac{\partial k}{\partial x_{j}}\right)++\overline{G_{k}}-Y_{k}+S_{k} \\
& \frac{\partial}{\partial t}(\rho \omega)+\frac{\partial}{\partial x_{j}}\left(\rho \omega u_{j}\right)=\frac{\partial}{\partial x_{j}}\left(\Gamma_{\omega} \frac{\partial \omega}{\partial x_{j}}\right)+\overline{G_{\omega}}-Y_{\omega}+D_{\omega}+S_{k}
\end{aligned}
$$

The advantages of SST $k-\omega$ are seen ability to solve Low-Reynolds at near wall and High-Reynolds at far field zones and to predict more accurately in non-equilibrium regions for boundary layer with adverse pressure gradients such as separation domains. The computational fluid dynamics code FLUENT was used in the present study. The governing equations are discretized by using the finite volume method. The pressure-velocity 
coupling is achieved through the SIMPLE algorithm. The Second Order Upwind scheme is defined for the discretization of the momentum equation.

\section{Computational Domains and Grids Generation}

The phenomenal flow at the gap between the front and rear propellers has been changed all time because these each propeller generated interaction forces then the whole domains with uniform inflow s hould be considered in boundary condition (Kaewkhiaw et al., 2016). Figure 2 shows computational domains considering full blade of the front and rear propellers which are carried out as same to the experiment. It is divided into two parts which are the rotating and stationary. The rotating regions are called Rotating which were contained front and rear propellers. The fixed region called Stationary. Both propellers are defined to rotate in the opposite directions. The boundary condition was imposed to simulate flow around the rotating propeller in the open water by moving reference systems for steady method. Moreover, It has been applied to unsteady method, blade to blade interaction forces are arrested by the flow field through the sliding mesh interface systems between the front and rear propellers including it can be interacted to each other. The time accuracy conducted by the time step size is 0.0002315 seconds which correspond to the propeller rotation angle of 1.0 degree.

No-s lip boundary conditions were defined for solid surfaces (blades and hubs). Free-slip boundary condition set for outer surface. Inlet component was set velocity inlet with the given inflow speed. Turbulence intensity and turbulence viscosity in this condition were used to $1 \%$. Outlet component set static pressure to constant equal zero. The computational domain dimensions are demonstrated as same to the both CRPs which is showed in Table 2 where $\mathrm{D}$ is front propeller diameter.

The grids of computational domains (rotating and stationary) are generated as same types by polyhedral cells for the both CRPs. The blade and hub surfaces were generated to finesse grid with small polyhedral cells. The other surfaces defined grid bigger than blade and hub. The polyhedral cells have been applied from the research of Morgut et al. (2009). The grid independence was investigated to propeller performance by separation in two different cases. The first case is called the baseline grid. The second, grid quality is refined to finesse which called the refined grid. The 3686-3687A propellers defined approximately 3M and 4M cells for total grids with the baseline and refined grids respectively. The 3686-3849 propellers were set approximately $3.2 \mathrm{M}$ and $4.2 \mathrm{M}$ cells for total grids with the baseline and refined grids respectively. The details of grid independence for the computational domains with the both CRPs are presented in Tables 3 and 4 respectively. Figure 3 shows the surface grids on a propeller blade. Figure 4 shows the grid of computational domains for rotating and stationary parts.

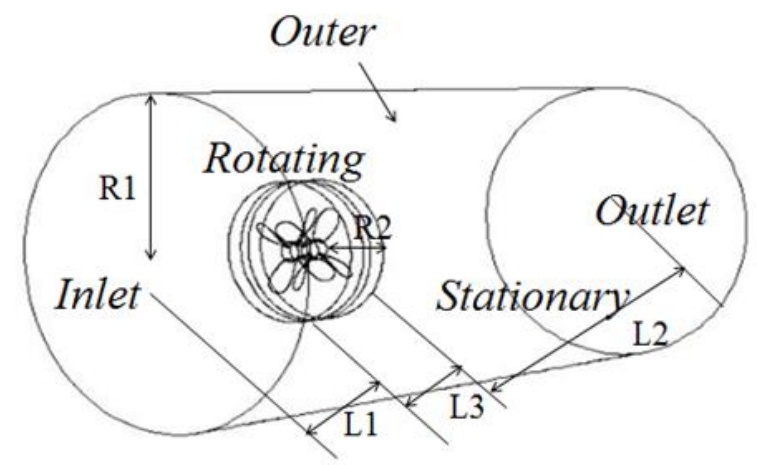

Table 2: Dimension of computational domains

\begin{tabular}{|c|c|c|}
\hline & Rotating & Stationary \\
\hline L1 & & $1.55 \mathrm{D}$ \\
\hline L2 & & $4.55 \mathrm{D}$ \\
\hline L3 & $0.43 \mathrm{D}$ & \\
\hline R1 & & $3.28 \mathrm{D}$ \\
\hline R2 & $0.72 \mathrm{D}$ & \\
\hline
\end{tabular}

Fig. 2: Computational domain of calculation

The numerical computations were performed on a PC with a 64-bit processor, Intel(R) Core(TM) i7-4790, CPU@3.60GHz, and 16 GB RAM. The processing time for calculation with baseline and refined grids using a parallel processor (8 CPU) was used time about 3 and 4 hours per an advance coefficient respectively for achieving residual convergence requirement of $1 \mathrm{e}^{-06}$ in all steady cases with the both CRPs. The unsteady cases are employed time about 30 hours per an advance coefficient for 6 cycles of propeller rotation with the both CRPs. 
Table 3: The configurations of computational grid for the 3686-3687A propellers

\begin{tabular}{|c|c|c|c|c|}
\hline & \multicolumn{2}{|c|}{ Rotating (Cells) } & Stationary (Cells) & \\
\hline Grid & Front Propeller & Rear Propeller & & Total (Cells) \\
\hline Baseline & $1.1 \mathrm{M}$ & $1.1 \mathrm{M}$ & $0.8 \mathrm{M}$ & $3 \mathrm{M}$ \\
\hline Refined & $1.6 \mathrm{M}$ & $1.6 \mathrm{M}$ & $0.8 \mathrm{M}$ & $4 \mathrm{M}$ \\
\hline
\end{tabular}

Table 4: The configurations of computational grid for the 3686-3849 propellers

\begin{tabular}{|c|c|c|c|c|}
\hline & \multicolumn{2}{|c|}{ Rotating (Cells) } & Stationary (Cells) & \\
\hline Grid & Front Propeller & Rear Propeller & & Total (Cells) \\
\hline Baseline & $1.1 \mathrm{M}$ & $1.4 \mathrm{M}$ & $0.7 \mathrm{M}$ & $3.2 \mathrm{M}$ \\
\hline Refined & $1.6 \mathrm{M}$ & $1.9 \mathrm{M}$ & $0.7 \mathrm{M}$ & $4.2 \mathrm{M}$ \\
\hline
\end{tabular}

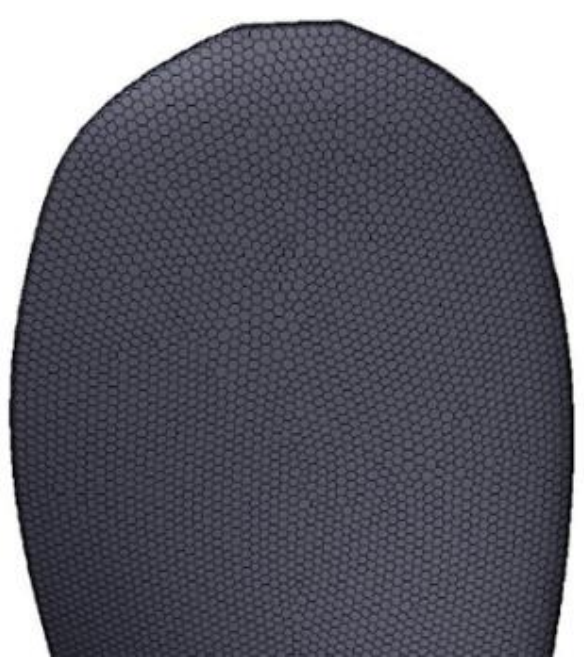

Fig. 3: Polyhedral cells on a blade of CRPs

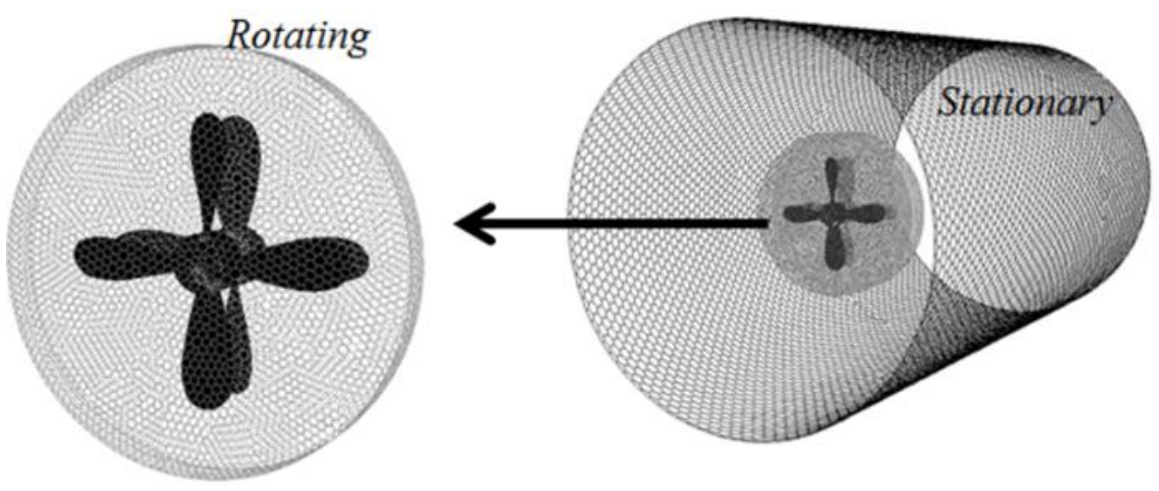

Fig. 4: Computational domains grid of rotating and stationary parts

\section{Test Problems Description}

\subsection{The steady method}

The investigating grid quality is studied to computational results for the both CRPs propeller performance. The first, 3686-3687A propellers have been used to simulation. Figure 5 shows the calculated results of propeller performance with different grid quality for front and rear propellers comparing the experimental data. Furthermore, the total thrust, torque coefficients and propeller efficiency of calculated results for grid independence are shown in Fig. 6 which corresponded to Fig. 5. It is found that the accuracy of calculated 
results for the baseline (red dot line) and refined grids (black solid line) showed consistent with the experiment. However, the accuracy of refined grid is showed better than the baseline grid.
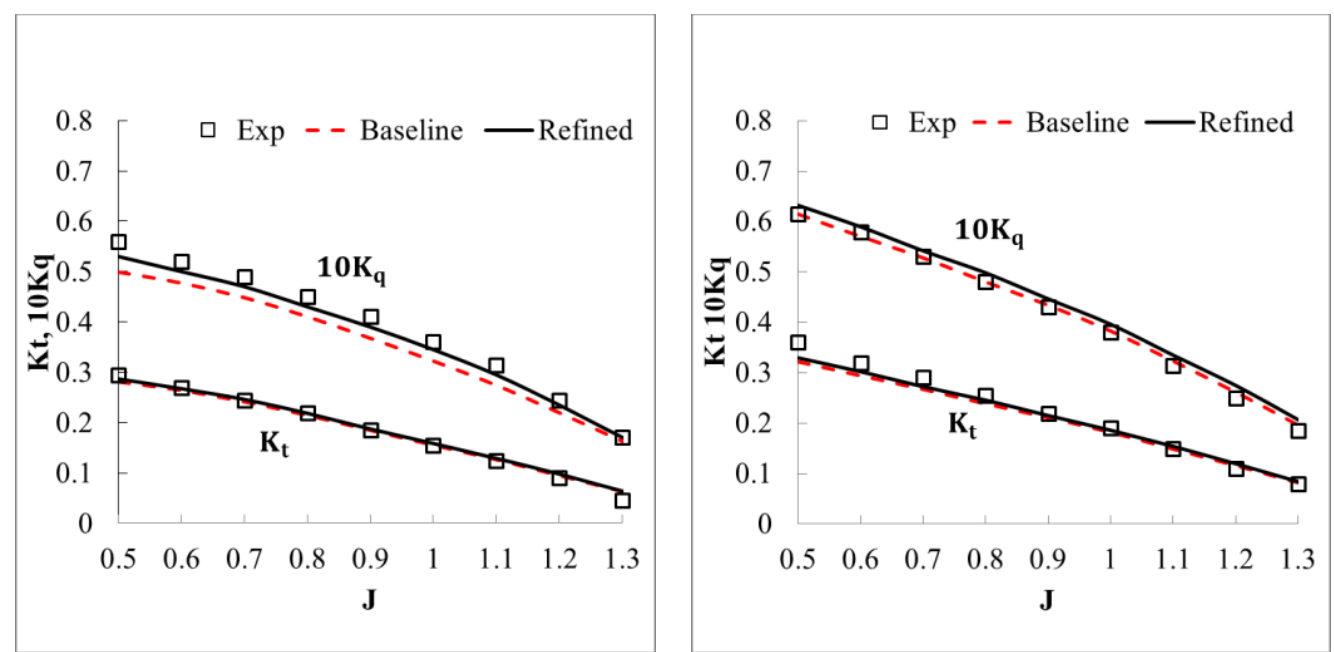

Fig. 5: Thrust and torque coefficients for front propeller (left hand) and rear propeller (right hand) with 3686$3687 \mathrm{~A}$

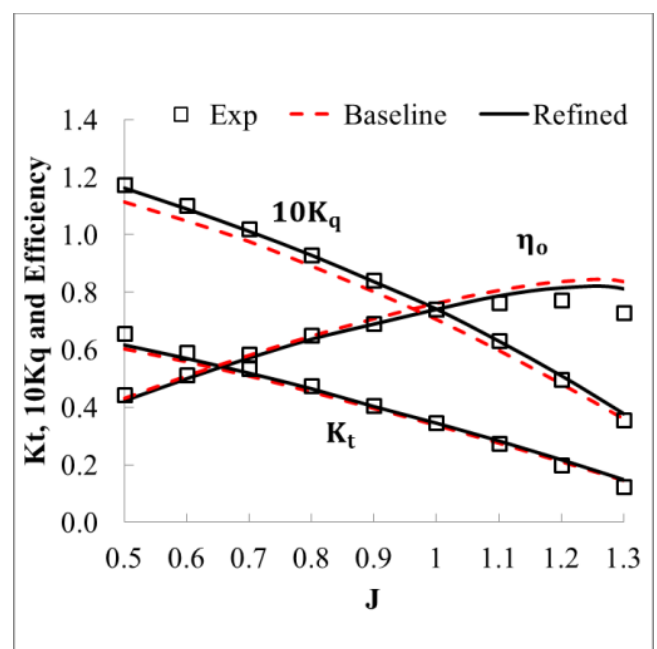

Fig. 6: Propeller performance with 3686-3687A
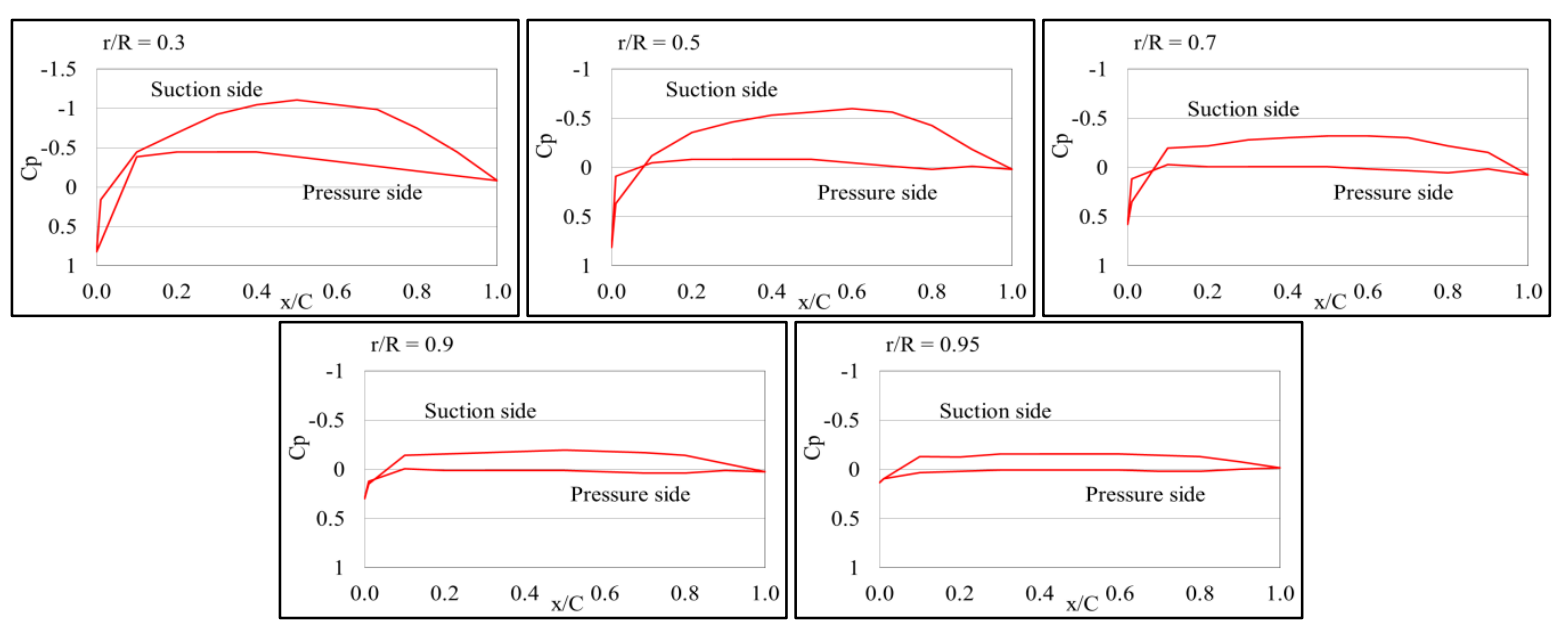

Fig. 7: Chordwise distribution of pressure coefficients on the blade, $r / R=0.3$ to 0.95 at design advance coefficient for front propeller with 3686-3687A 
In addition, it is found that calculated results of torque coefficients for front propeller seemed that slightly decreased to experimental data at advance coefficients, $\mathrm{J}=0.5-1.1$ but thrust coefficients were agreed well to measured data at each range of advance coefficients. The calculated results of torque coefficients for rear propeller found that slightly increased to the measured data but thrust coefficients are agreed with the experimental data. In addition, total thrust, torque coefficients and propeller efficiency of computational results and measured data are good relations including at design advance coefficient, $\mathrm{J}=1.1$. Figures 7 and 8 show calculation results of the pressure coefficient distributions on the blade, $\mathrm{r} / \mathrm{R}=0.3$ to 0.95 at design advance coefficient for front and rear propellers respectively, which is corresponded to propeller performance.

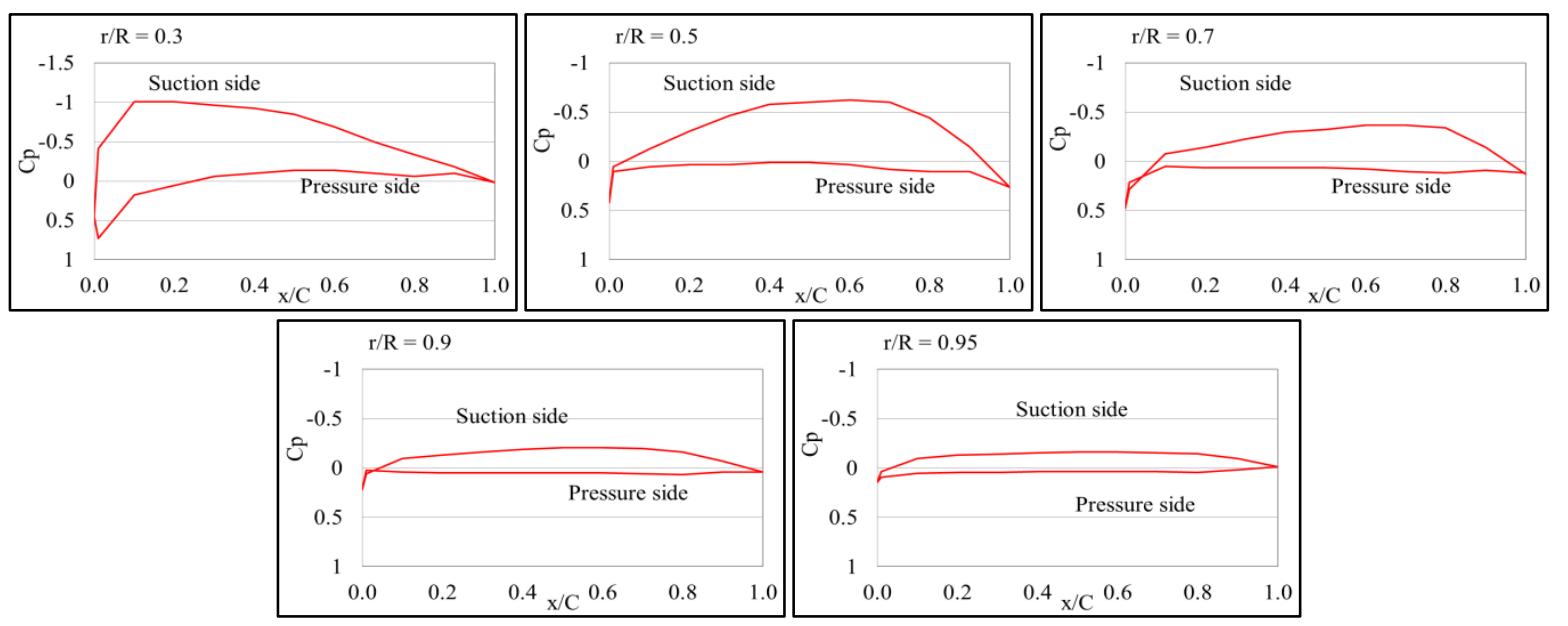

Fig. 8: Chordwise distribution of pressure coefficients on the blade, $r / R=0.3$ to 0.95 at design advance coefficient for rear propeller with 3686-3687A

The second, 3686-3849 propellers were defined to evaluate propeller performance at the same previous propellers condition. Fig. 9 shows the calculated results of thrust and torque coefficients with different grid quality for front and rear propellers comparing the measured data. Moreover, the total thrust, torque coefficients and propeller efficiency are shown in Fig. 10 which corresponded to Fig. 9. It can be seen that accuracy of computational results for the baseline (red dot line) and refined grids (black solid line) showed very good to the experimental data at each range of advance coefficients including at design advance coefficient, $\mathrm{J}=1.1$. However, the maximum percentage error of propeller performance for calculated results with the both CRPs propellers occurred about lower than 5\% at each range of the advance coefficient. Figures 11 and 12 show calculated results of the pressure coefficient distribution on the blade, $\mathrm{r} / \mathrm{R}=0.3$ to 0.95 at design advance coefficients for front and rear propellers respectively which is corresponded to propeller performance.

Fig. 13 shows the comparison of velocity vectors contours for calculations with 3686-3687A and 3686-3849 between the position A (middle of area to the front and rear propellers) at upper and the position B (behind of area to the rear propeller) at lower where are located about $21.6 \mathrm{~mm}$ and $120 \mathrm{~mm}$ from centerlines of the front propeller respectively. The positions $\mathrm{A}$ and $\mathrm{B}$ are defined to same the distances from the front and rear propellers. It is clearly seen that velocity gradient of the propeller disk area at position A is higher than at position B due to the energy transformation between the front and rear propellers have occurred at position A. In addition, the effect of interaction forces at position $\mathrm{A}$ is induced into becoming the entry flow for rear propeller which is directly affected to generate forces of rear propeller. 

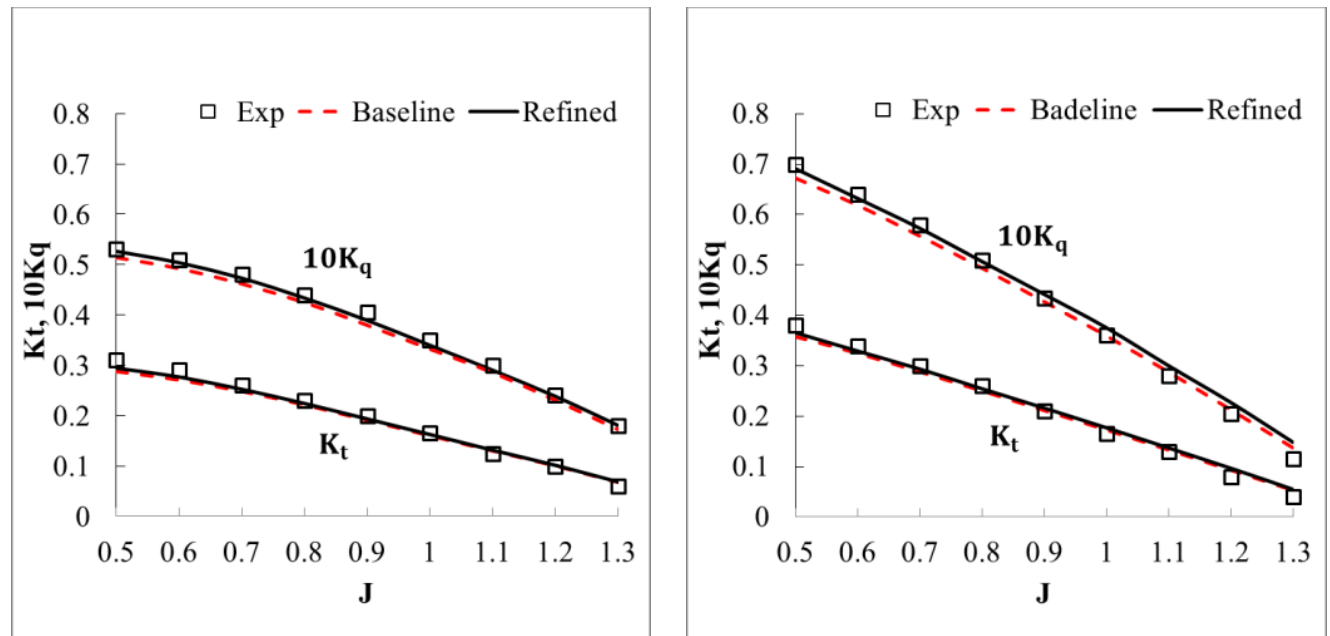

Fig. 9: Thrust and torque coefficients for front propeller (left hand) and rear propellers (right hand) with 36863849

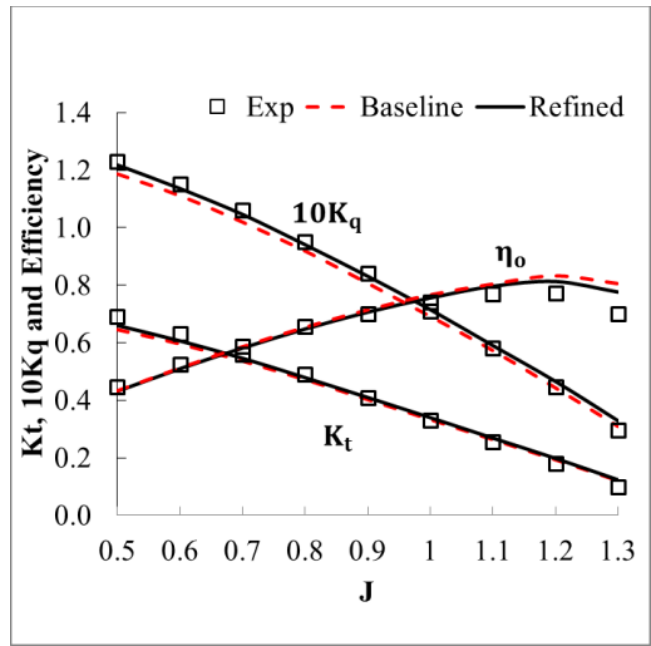

Fig. 10: Propeller performance with 3686-3849

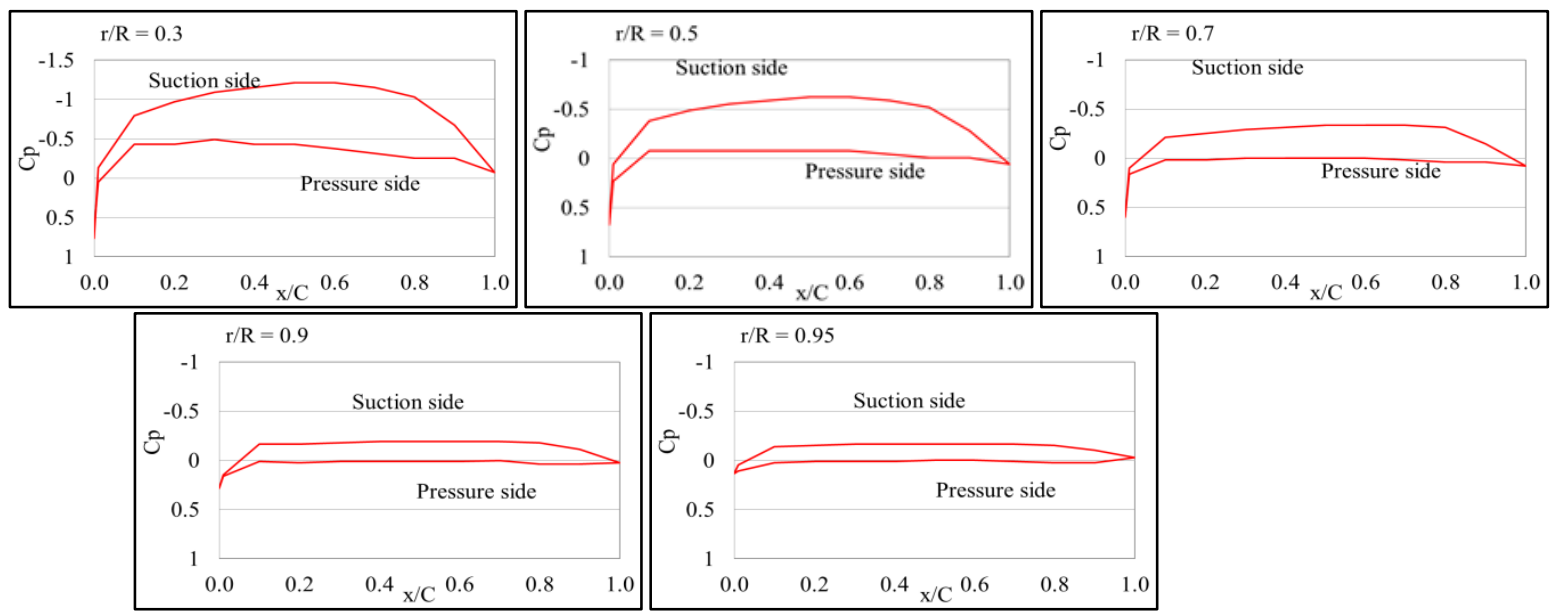

Fig. 11: Chordwise distribution of pressure coefficients on the blade, $r / R=0.3$ to 0.95 at design advance coefficient for front propeller with 3686-3849 


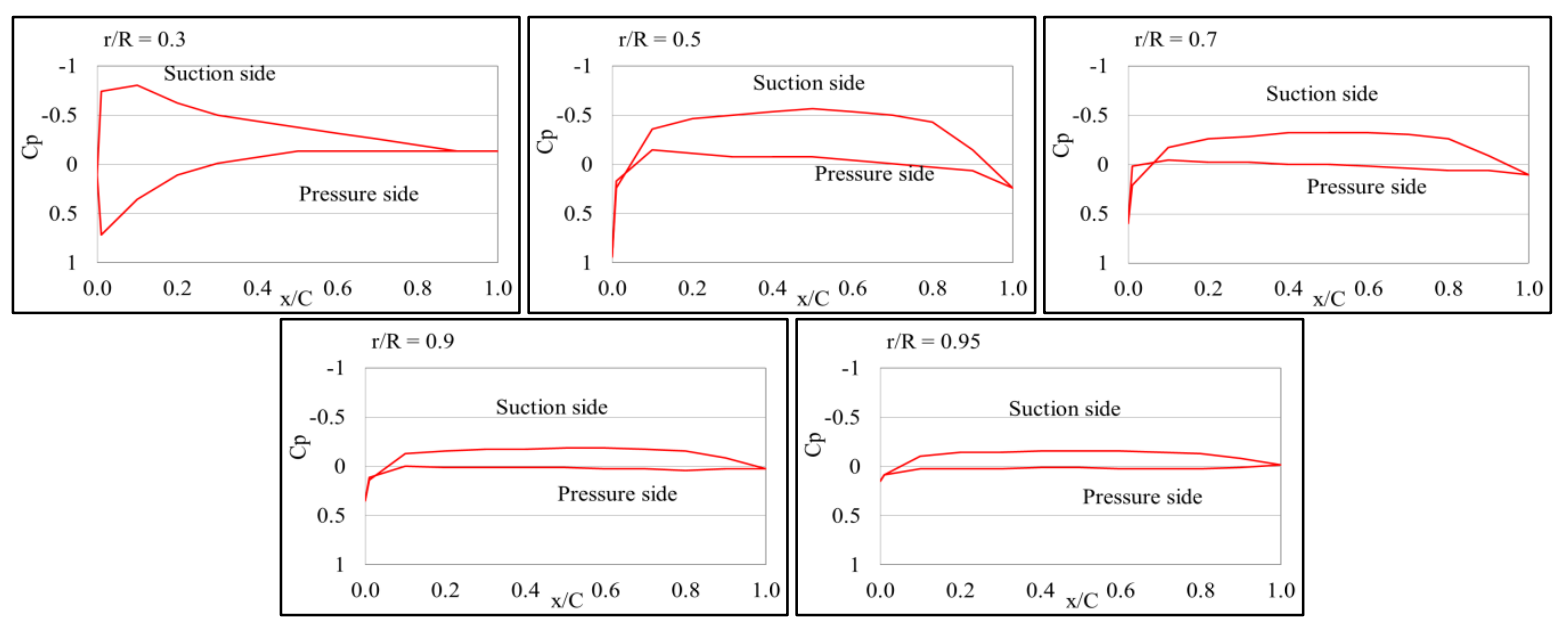

Fig. 12: Chordwise distribution of pressure coefficients on the blade, $r / R=0.3$ to 0.95 at design advance coefficient for rear propeller with 3686-3849
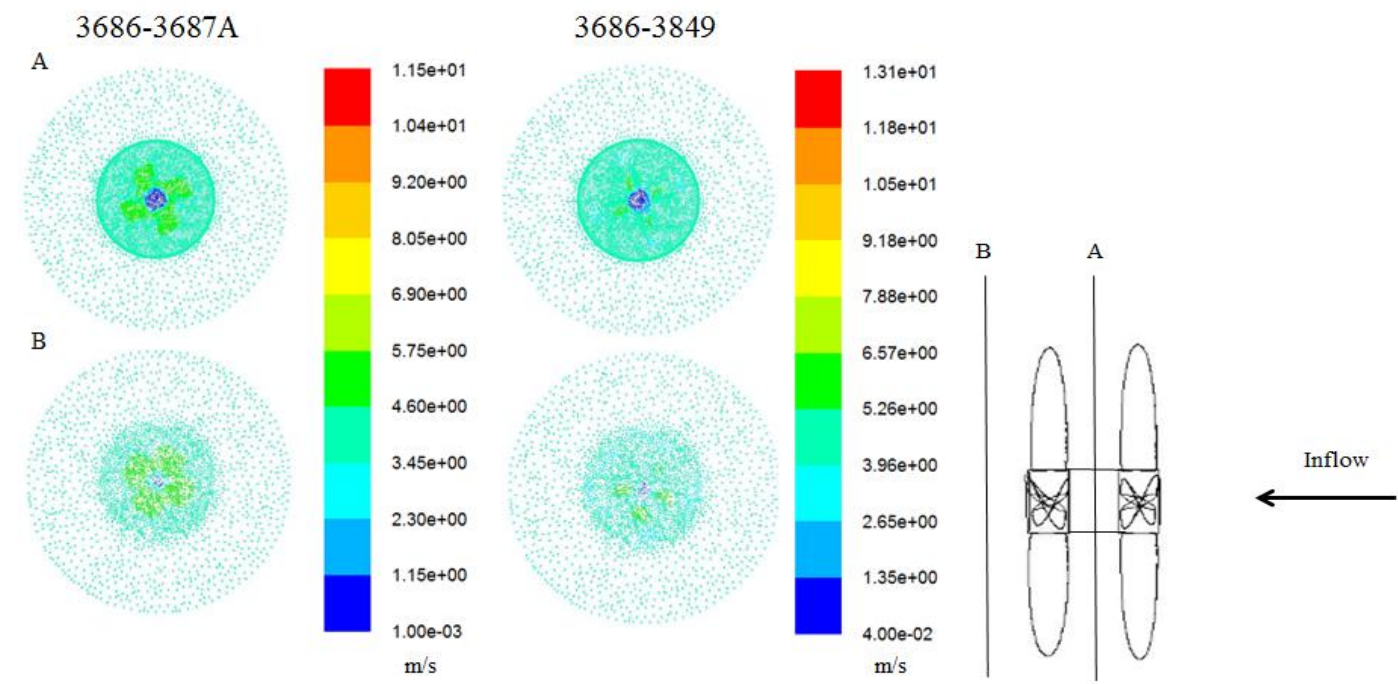

Fig. 13: Velocity vector magnitude contours at the middle of areas between the front and rear propellers, position A (upper) and behind of areas to the rear propeller, position B (lower) at design advanced coefficient with $3686-3687 \mathrm{~A}$ and $3686-3849$ respectively

\subsection{The unsteady method}

The both CRPs propeller models (3686-3687A and 3686-3849) have been analysed to evaluate propeller performance with time accuracy at design advanced coefficient, $\mathrm{J}=1.1$. ( $\mathrm{J}$ is based on front propeller diameter in Table 1). The uniform inflow is imposed at each time step in the time domain. The rotation angle of the front and rear propellers are varied one degree per time step size $(0.0002315$ seconds per a degree) therefore realistic flow on each blade including at the gap between the front and rear propellers have generated interaction forces from themselves with real time.

Fig. 14 shows calculated results of single blade thrust and torque coefficients for front and rear propellers with 3686-3687A as one rotational. The front and rear propellers generated torque coefficients with fluctuation which are almost the same average value in the different directions. The phase angle in a loop circle demonstrated about 45 degrees for the front propeller. But, torque line of the rear propeller has oscillated which will not be smoothly for the amplitude because of the effect of interaction force from the front propeller. Finally, total torque with them are eliminated and it makes that into balance. It is found that thrust coefficient for front and rear propellers seemed fluctuation. The average thrust of the rear propeller showed slightly higher than the front propeller. Moreover, thrust line of the rear propeller is generated amplitude which was not smoothly. The main 
reasons because the effect of flow phenomenal which enter to the rear propeller from outflow of the front propeller.

Simultaneously, the single blade thrust and torque coefficients for front and rear propellers with 3686-3849 as one rotational is shown in Fig. 15. It is found that the torque coefficient of the front and rear propellers fluctuated with different directions as same as the 3686-3687A. However, torque line of rear propeller has not been run smoothly for the amplitude fluctuation as same as the rear propeller of the 3686-3687A. Moreover, the average value of torque for rear propeller showed slightly lower than the front propeller. The average thrus $t$ coefficient of rear propeller seemed to decrease than the rear propeller of the 3686-3687A. The one reas on for decreasing of average value the thrust and torque for the rear propeller with 3686-3849 compared the rear propeller with 3686-3687A because the effect of fluid flow interacted from the front propeller including the number of blades are used to difference between the both CRPs. (Front and rear propellers of 3686-3687A have used four blades but front propeller of 3686-3849 used four blades and rear propeller set five blades). It is found that only front propellers with the both CRPs (3686-3687A and 3686-3849), thrust and torque lines seemed similar values including fluctuation curves because fluid interaction from rear propellers have not sent to front propellers so much. In addition, the flow will enter to the front propeller in the first order.
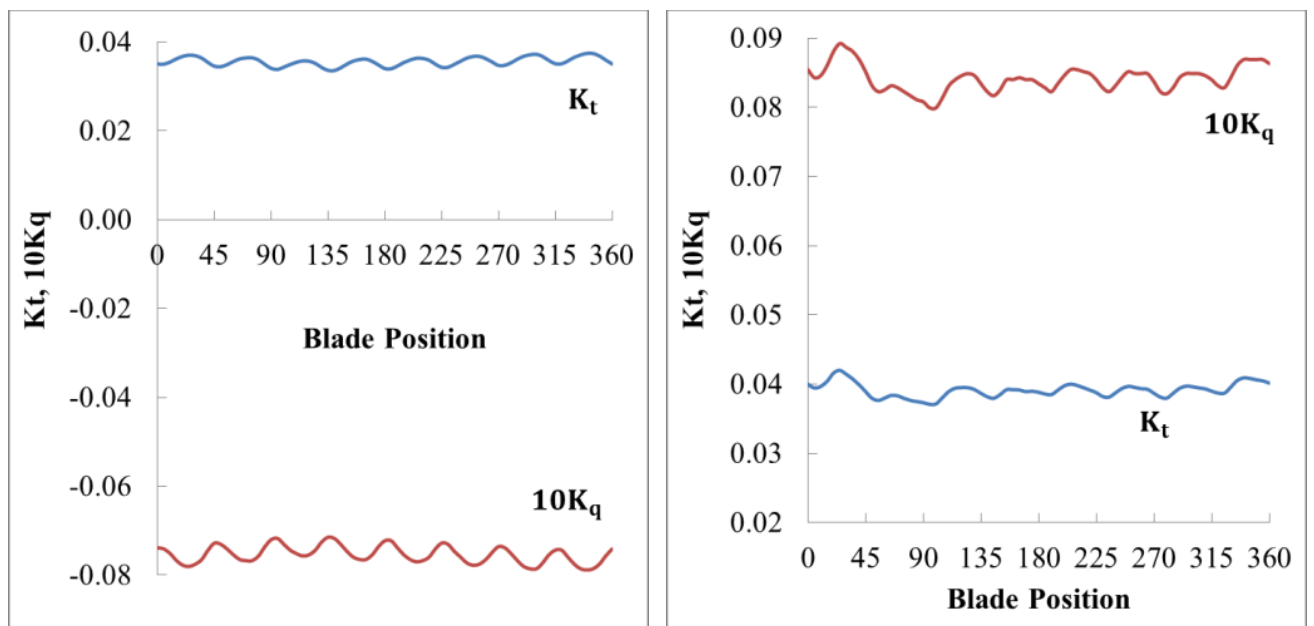

Fig. 14: Single blade thrust and torque coefficients for front propeller (left hand) and rear propeller (right hand) as functions of blade position at design advance coefficient with 3686-3687A
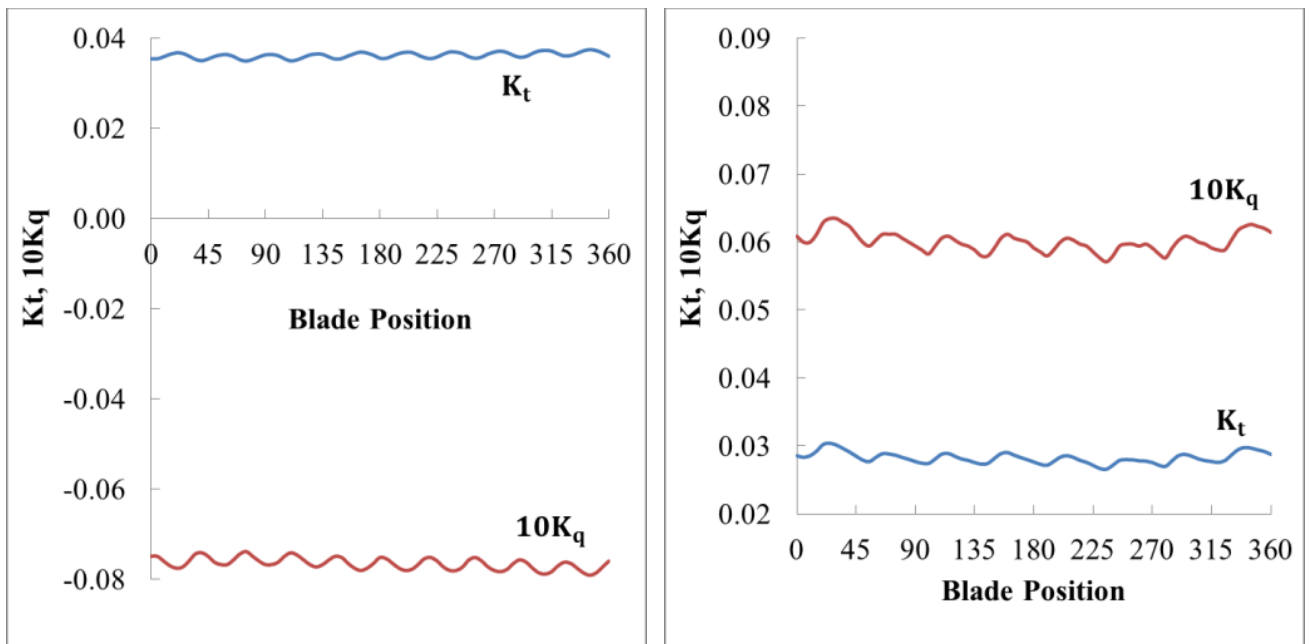

Fig. 15: Single blade thrust and torque coefficients for front propeller (left hand) and rear propeller (right hand) as functions of blade position at design advance coefficient with 3686-3849

Propeller performance for average thrust and torque coefficients of the front and rear propellers with the both 
CRPs (3686-3687A and 3686-3849) comparing the experimental data at design advanced coefficient are presented in Tables 5 and 6 respectively. The experiment of 3686-3687A is clearly seen that thrust coefficient of the rear propeller is generated higher than the front propeller while the torque coefficient of the front and rear propellers are found to same the values. The one reasons of all because the propeller pitch of the rear propeller is defined more than the front propeller. Moreover, the torque of rear propeller should be higher than front propeller but it is not so because wake from the front propeller will interrupt to generating torque of rear propeller.

In addition, the experimental data of 3686-3849 is seen that torque coefficient of the rear propeller is generated slightly lower than the front propeller. The reason because the propellers pitch of the rear propeller is set lower than the front propeller including the effect from the wake of the front propeller. While the thrust coefficient of the front and rear propellers are found to same the values because the number of the blade in rear propeller is set more than the front propeller (front propeller set 4 blades, rear propeller set 5 blades). In fact, the thrust of rear propeller should be lower than the front propeller because propeller pitch is lower. However, it was clearly seen that the calculated results were in good agreement with the experiment for both CRPs.

Figs. 16 and 17 show the calculated results of the pressure coefficient distributions on the blade, $r / R=0.7$ at two different rotation angles, $0^{\circ}$ and $180^{\circ}$ for front and rear propellers with 3686-3687A and 3686-3849 respectively. The angle of 0 degree corresponded to the top position and the angle increases in the clockwise and counterclockwise directions for front and rear propellers respectively. It is found that the pressure coefficient of both angles seemed to be similar which correspond to the results in Tables 5 and 6.

Table 5: Comparisons of thrust and torque coefficients for the front and rear propellers with 3686-3687A between calculation and experiment at design advanced coefficient

\begin{tabular}{|c|c|c|c|c|}
\hline Items & $\mathrm{K}_{\mathrm{t}}($ Front $)$ & $10 \mathrm{~K}_{\mathrm{q}}($ Front $)$ & $\mathrm{K}_{\mathrm{t}}($ Rear $)$ & $10 \mathrm{~K}_{\mathrm{q}}($ Rear $)$ \\
\hline Calculation & 0.130 & 0.310 & 0.157 & 0.320 \\
\hline Experiment & 0.125 & 0.315 & 0.150 & 0.315 \\
\hline
\end{tabular}

Table 6: Comparisons of thrust and torque coefficients for the front and rear propellers with 3686-3849 between calculation and experiment at design advanced coefficient

\begin{tabular}{|c|c|c|c|c|}
\hline Items & $\mathrm{K}_{\mathrm{t}}($ Front $)$ & $10 \mathrm{~K}_{\mathrm{q}}($ Front $)$ & $\mathrm{K}_{\mathrm{t}}($ Rear $)$ & $10 \mathrm{~K}_{\mathrm{q}}($ Rear $)$ \\
\hline Calculation & 0.131 & 0.295 & 0.135 & 0.290 \\
\hline Experiment & 0.130 & 0.300 & 0.130 & 0.280 \\
\hline
\end{tabular}
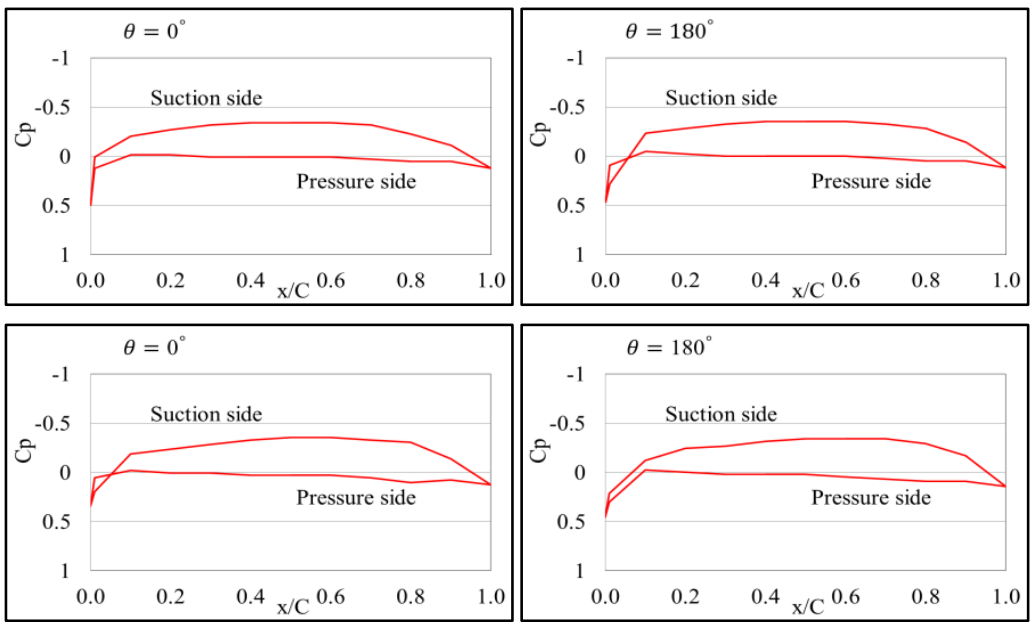

Fig. 16: Chordwise distribution of pressure coefficients on the blade, $r / R=0.7$ at rotation angles, $\theta=0^{\circ}$ and $180^{\circ}$ respectively for front propeller (upper) and rear propeller (lower) with 3686-3687A 


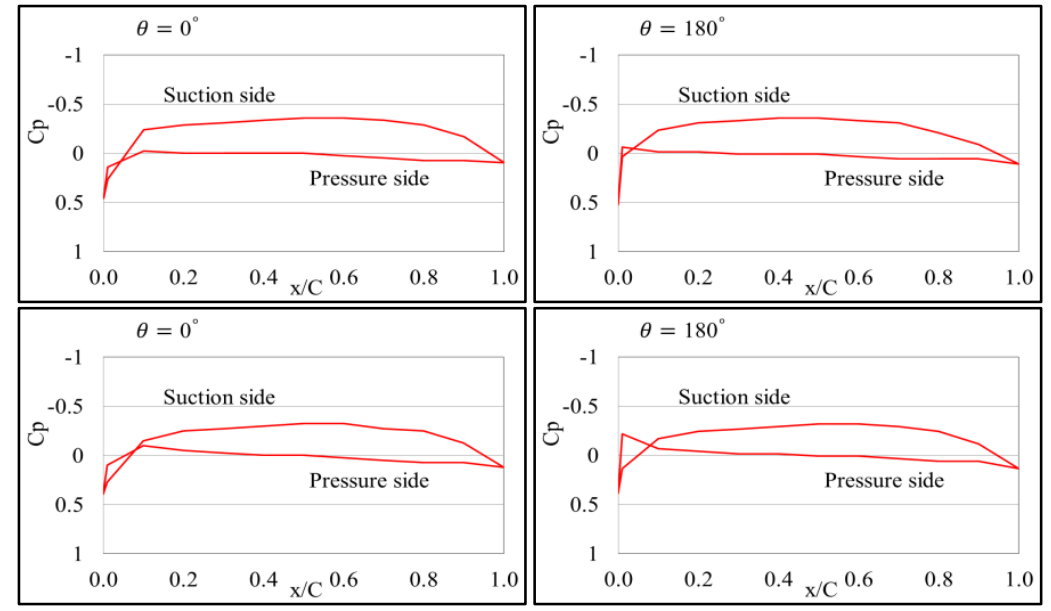

Fig. 17: Chordwise distribution of pressure coefficients on the blade, $r / R=0.7$ at rotation angles, $\theta=0^{\circ}$ and $180^{\circ}$ respectively for front propeller (upper) and rear propeller (lower) with 3686-3849

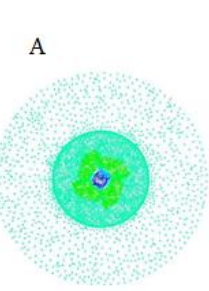

B

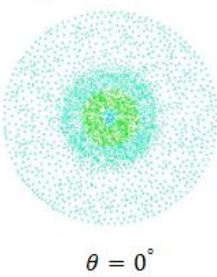

A

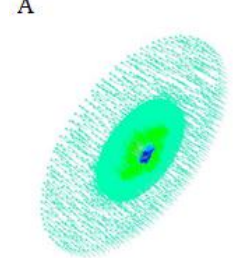

B

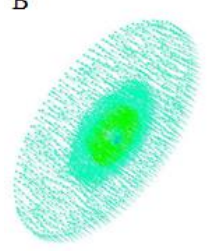

$\theta=0^{\circ}$
Front view
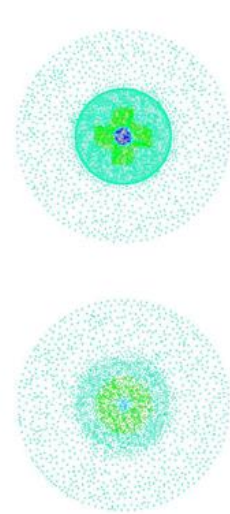

$\theta=120^{\circ}$

Isometric view
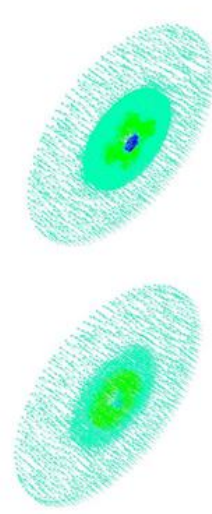

$\theta=120^{\circ}$
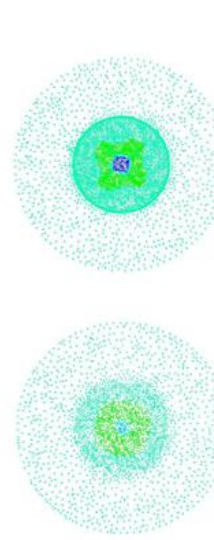

$\theta=240^{\circ}$

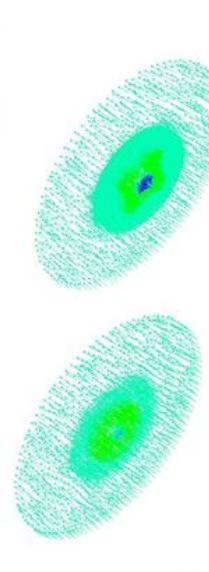

$\theta=240^{\circ}$

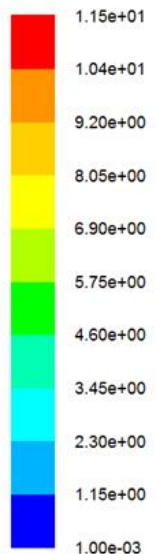

1.000

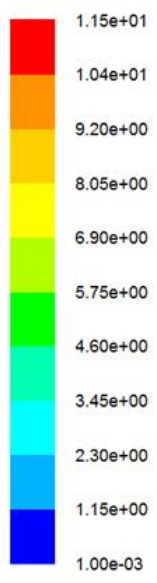

$\mathrm{m} / \mathrm{s}$
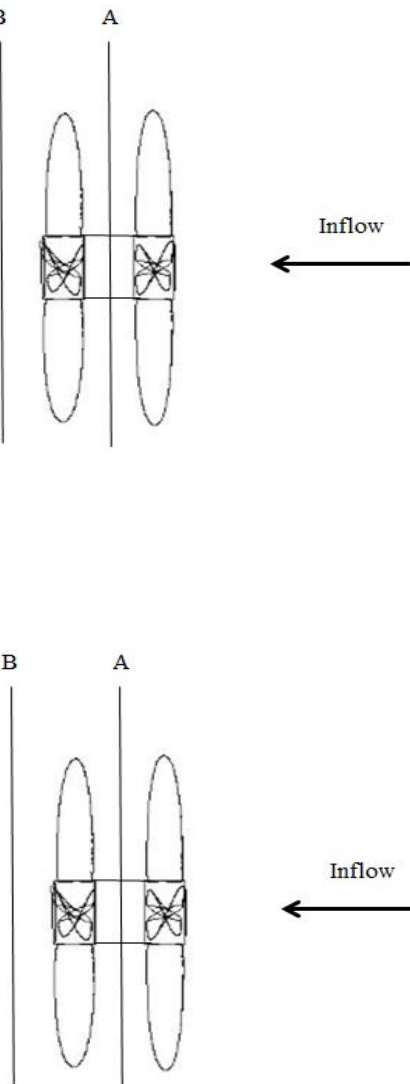

Inflow

Fig. 18: Velocity vector magnitude contours at the middle of areas between the front and rear propellers, position A (upper) and behind of areas to the rear propeller, position B (lower) as functions of blade position at design advanced coefficient with 3686-3687A

Figs. 18 and 19 show the comparisons of velocity vectors contours for calculated results with 3686-3687A and 3686-3849 propellers between the position A (middle of area between the front and rear propellers) at upper and the position B (behind of area to the rear propeller) at lower as functions of blade positions approximately $0^{\circ}$, 


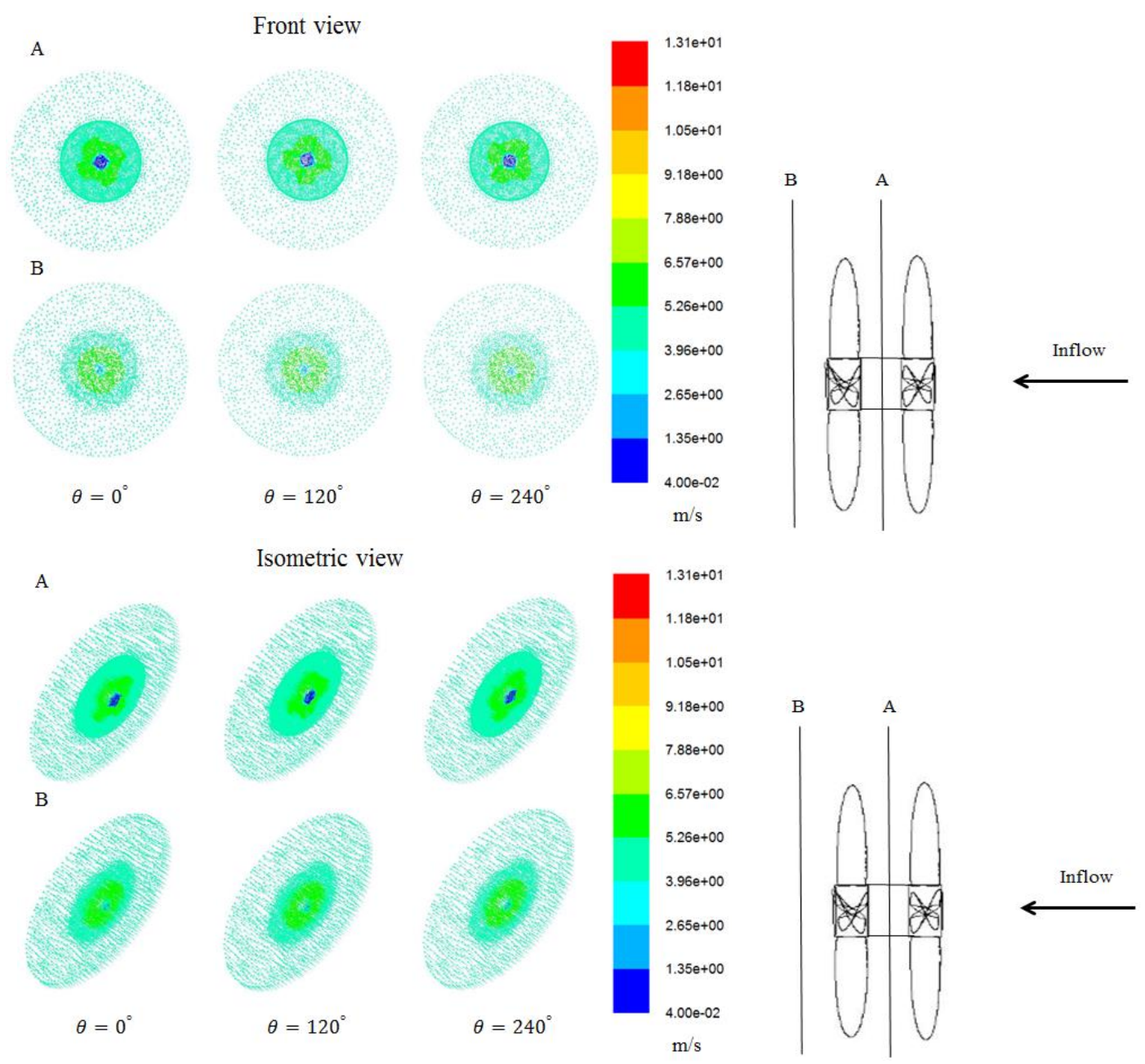

Fig. 19: Velocity vector magnitude contours at the middle of areas between the front and rear propellers, position A (upper) and behind of areas to the rear propeller, position B (lower) as functions of blade position at design advanced coefficient with 3686-3849

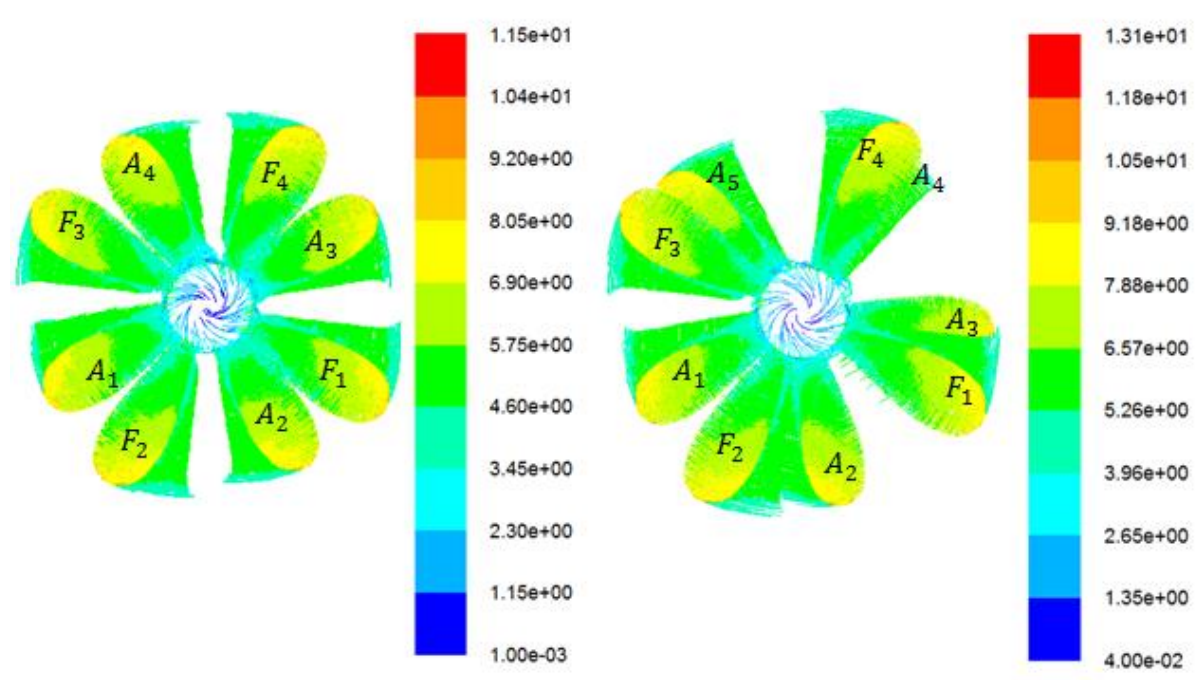

Fig. 20: Iso-surfaces of velocity vector magnitude $(\mathrm{m} / \mathrm{s})$ as functions of blade position $\left(\theta=120^{\circ}\right)$ with 36863687A (left) and 3686-3849 (right) respectively 
$120^{\circ}$ and $240^{\circ}$ respectively. The positions A and B have been defined as same as the previous section (steady method). The spot in circles of the figure means the propeller disk area which views upstream to downstream. It is found that the propeller disk area at position A where it is interacted to momentum energy between the front and rear propellers then the velocity gradient is higher than the position B at each angular position. The interaction forces at the position A affected to acceleration velocity on the blade of rear propeller including the area at position $\mathrm{B}$.

Fig. 20 shows the Iso-surface of velocity vectors on the blade of the front and rear propellers with 3686-3687A and 3686-3849. The definition of $F_{1}$ to $F_{4}$ are mean that each blade of the front propeller which rotated clockwise when observation from upstream to downstream. The definition of $A_{1}$ to $A_{4}$ including $A_{5}$ are mean that each blade of the rear propeller which rotated counterclockwise when observation from upstream to downstream. It seemed that the shape of velocity on each blade between the front and rear propellers are few different values with the both CRPs which affected to the thrust and torque coefficients of the front and rear propellers corresponding to the results as shown in Figs. 14 and 15.

\section{Conclusions}

The computed propeller characterisitics using steady method based on RANS for the front and rear propellers (3686-3687A and 3686-3849) are compared with the experimental data and are found in good agreement at different advance coefficients including design advance coefficient.

Using the unsteady method, the computed amplitudes of thrust and torque coefficients for the front propeller with the both CRPs are fluctuated smoothly considering one complete revolution. But the amplitude of thrust and torque coefficients for the rear propeller with the both CRPs are not fluctuated smoothly because of interaction forces from the front propeller. In case of the 3686-3687A propeller, average thrust coefficient for the rear propeller is slightly higher than the front propeller because the pitch of the rear propeller is higher than the front propeller although it has interacted force from the front propeller. On the otherhand, the average thrust coefficients for the front and rear propellers (3686-3849) are found similar. Since the pitch of the rear propeller is lower than the front propeller, it is compensated by using higher number of blade. Duet to the interaction forces in the middle of the area between the front and rear propellers with both CRPs, velocity vector magnitude contours are found higher than those at the behind area to the rear propeller. In addition, the calculated results of the front and rear propellers (3686-3687A and 3686-3849) agreed well with the experimental values at design advanced coefficient.

The above results can help to design CRPs. Care must be taken to consider the propeller pitch and the number of propeller blades for the front and rear propellers. Those principal particulars can be used substitution which has affected to propeller performance of CRPs. In addition, considerations should be taken for the propeller diameter in each propeller including the gap distance between the front and rear propellers the variation of which has influence on propeller performance of CRP. However, not many variations of propeller diameter of the front and rear propellers were considered in this research.

\section{Acknowledgement}

ANSYS Fluent software used in this research is supported by Faculty of Engineering at Si Racha, Kasetsart University, Sri Racha Campus.

\section{References}

Gu, H. and Kinnas, S. (2003): Modeling of contra-rotating and ducted propeller via coupling of a votex-lattice with a finite volume method, Propellers/Shafting symposium, SNAME, Virginia, USA.

Grassi, D., Brizzolara, S., Viviani, M., Savio, L. and Caviglia, S. (2010): Desing and analysis of counterrotationg-comparis on of numerical and experimental results, The 9th ICHD, China.

Hoshino, T. (1994): Experimental and theoretical analysis of propeller shaft forces of contra-rotating propeller and correlation with full scale data, The Propellers/Shafting 94 symposium, SNAME, Virginia, U.S.A. 
Inukai, Y. (2011): Development of contra-rotating propeller with tip-raked fins, SMP'11, Hamburg, Germany. Inukai, Y., Kanemaru, T. and Ando, J. (2014): Prediction of steady performance of contra-rotating propellers including wake alignment, The 11th ICHD, Singapore.

Inukai, Y., Kanemaru, T. and Ando, J (2015): Prediction of steady performance of contra-rotating propellers with rudder, SMP'15, Texas, USA.

Kaewkhiaw, P., Yodchai, T., Dechauophai, P. and Juntasaro, V. (2011): Application of nonlinear turbulence models for marine propulsors, Journal of Fluids Engineering, ASME, Vol. 133, No. 3, pp. 101-107. https://doi.org/10.1115/1.4003564

Kaewkhiaw, P. and Ando, J. (2014): Numerical simulation for unsteady propeller performance with inclined shaft propeller arrangement using CFD, The 11th ICHD, Singapore.

Kaewkhiaw, P., Yoshitake, A., Kanemaru, T. and Ando, J. (2016): Evaluation of thai long-tail boat propeller performance and its improvement, 12th ICHD, Netherland.

Miller, M.L. (1976): Experimental determination of unsteady forces on contra-rotating propellers in uniform flow, David Taylor Naval Ship Research and Development Center, Report No. DTNSRDC/SPD-0659-01, Bethes da, Maryland, USA.

Miller, M.L. (1981): Experimental determination of unsteady forces on contra-rotating propellers for application to torpedoes, David Taylor Naval Ship Research and Development Center, Report No. DTNSRDC/SPD-065902, Bethesda, Maryland, USA.

Morgut, M. and Nobile, E. (2009): Comparis on of hexa-structured and hybrid-unstuctured meshing approaches for numerical prediction of the flow around marine propellers, SMP'09, Trondheim, Norway.

Paik, B.G., Kim, J., Park, Y.H., Kim, K.S. and Kim, K.Y. (2005): PIV analys is of votical flow behind a rotating propeller in a cavitation tunnel, Journal of the Society of Naval Architects of Korea, Vol. 42, No. 6, pp.619-630. https://doi.org/10.3744/snak.2005.42.6.619

Paik, K.J., Seo, S.B. and Chun, H.H. (2000): Analysis of contra-rotating propellers in steady flow by a vortex lattice method, Journal of the Korean Society of Ocean Engineers, Vol. 14, No. 2, pp 36-43.

Tsakonas, S., Jacobs, W. and Liao, P. (1983): Prediction of steady and unsteady loads and hydrodynamic forces on counter-rotating propellers, Journal of Ship Research, Vol. 27, No. 3, pp.197-214.

Yang, C.J., Wang, G., Tamashima, M. and Yamazaki, R. (1991): Prediction of steady performance of contrarotating propellers by lifting surface theory, Trans. of West-Japan Society of Naval Architects, Vol. 82, 17-31.

Yang, C.J., Wang, G., Tamashima, M. and Yamazaki. R. (1992): Prediction of unsteady performance of contrarotating propellers by lifting surface theory, Trans. of West-Japan Society of Naval Architects, Vol. 83, 47-65. 